\title{
Specific issues after surgical repair of partial atrioventricular septal defect: Actuarial survival, freedom from reoperation, fate of the left atrioventricular valve, prevalence of left ventricular outflow tract obstruction, and other events
}

\author{
Ujjwal K. Chowdhury, MCh, Diplomate NB, ${ }^{\text {a } B a l r a m ~ A i r a n, ~ M C h, ~}{ }^{a}$ Amber Malhotra, MCh, ${ }^{\text {a Akshay K. Bisoi, MCh, }}$ \\ Mani Kalaivani, MSc (Biostatistics), ${ }^{\mathrm{b}}$ Raghu M. Govindappa, MS, ${ }^{\mathrm{a}}$ and Panangipalli Venugopal, $\mathrm{MCh}^{\mathrm{a}}$
}

\begin{abstract}
Objective: Our aim was to define the prevalence of specific sequelae after repair of partial atrioventricular septal defect.

Patients and Methods: A total of 132 consecutive patients undergoing repair of partial atrioventricular septal defect were studied for mortality, left atrioventricular valve function, reoperations, left ventricular outflow tract obstruction, and supraventricular arrhythmias. Age was 2.5 months to 43 years (median, 54 months); 13 (9.8\%) were more than 20 years old. Preoperatively, 26.5\% patients were in New York Heart Association class III/IV, $15.9 \%$ had supraventricular arrhythmias, $25.7 \%$ had pulmonary artery hypertension, 16.6\% had moderate-tosevere left valvular regurgitation, and $29.5 \%$ had additional left atrioventricular valvular malformations. Autologous pericardium $(n=127)$ and right atrial patch $(n=5)$ were used to patch the defect. Left atrioventricular valvuloplasty was performed in $91 \%$ of patients despite older age and additional malformations of the left atrioventricular valve.
\end{abstract}

Results: Operative and late mortalities were $4.5 \%$ and $3.2 \%$, respectively. Postoperative supraventricular arrhythmias were observed in $11.3 \%$ of patients. Reoperations were required in $5.8 \%$ patients because of a residual atrial septal defect $(n=1)$ and severe left atrioventricular valvular regurgitation $(n=6)$. At a mean follow-up of $106.82 \pm 55.04$ months, actuarial survival was $83.70 \% \pm 0.07 \%$. The risk of death was 38.92 (95\% confidence intervals: 7.8-195.1) and 6.88 (95\% confidence intervals: 1.79-38.18) times higher in patients with grossly malformed left atrioventricular valve and preoperative pulmonary artery hypertension, respectively, by logistic regression analysis.

Conclusions: Detailed assessment of the valve morphology and individualized valvuloplasty techniques improves the long-term survival after repair of partial atrioventricular septal defects. The presence of grossly malformed left valvular apparatus, pulmonary artery hypertension, and moderate-to-severe left atrioventricular valve regurgitation are independent predictors of death and defect-related morbidity after surgical repair.

Supplemental material is available online.

Despite standardized operative and postoperative management strategies of partial atrioventricular septal defects (AVSDs) during the past decade, repair of partial AVSDs continues to be associated with varying degrees of postoper-

From the Departments of Cardiothoracic Surgery ${ }^{\mathrm{a}}$ and Biostatistics, ${ }^{\mathrm{b}}$ AIIMS, New Delhi, India.

Received for publication Nov 26, 2007; revisions received Feb 26, 2008; accepted for publication April 3, 2008.

Address for reprints: Ujjwal K. Chowdhury, MCh, Diplomate NB, Department of Cardiothoracic and Vascular Surgery, All India Institute of Medical Sciences, New Delhi-110029, India (E-mail: ujjwalchow@rediffmail.com; ujjwalchowdhury@ gmail.com).

J Thorac Cardiovasc Surg 2009; 137:548-55

$0022-5223 / \$ 36.00$

Copyright (C) 2009 by The American Association for Thoracic Surgery

doi:10.1016/j.jtcvs.2008.04.035 ative left atrioventricular valve regurgitation, supraventricular arrhythmias, late mortality, and morbidity. ${ }^{\text {E1-E11 }}$

Although the severity of congestive heart failure, levels of pulmonary artery (PA) pressure and pulmonary vascular resistance (PVR), degree of left atrioventricular valve regurgitation, older age, date of operation, and low body surface area have been variously implicated as the causative factors for continuing surgical mortality and morbidity, there is as yet an insufficient appreciation of the morphologic heterogeneity of the left atrioventricular valvular apparatus that may determine the postoperative outcome of repaired partial AVSDs. ${ }^{\text {E1-E12 }}$

The objectives of this retrospective study were (1) to identify the morphologic characteristics, (2) to assess the degree of severity of postoperative left atrioventricular valve regurgitation both clinically and echocardiographically, (3) to determine the risk factors associated with mortality and morbidity, (4) to determine the incidence of cardiac reoperations, anatomic and surgical determinants of postoperative left atrioventricular valve insufficiency and stenosis, the 

Abbreviations and Acronyms
ASD $=$ atrial septal defect
AVSD $=$ atrioventricular septal defect
$\mathrm{CI}=$ confidence interval
NYHA $=$ New York Heart Association
LVOT $=$ left ventricular outflow tract
$\mathrm{PA}=$ pulmonary artery
PVR = pulmonary vascular resistance

prevalence of significant left ventricular outflow tract (LVOT) obstruction, and the frequency of early and late supraventricular arrhythmias, and finally (5) to provide certain guidelines for an individualized surgical approach.

\section{PATIENTS AND METHODS Original Cohort}

Between January 1991 and December 2006, a total of 132 patients (69 male) who had undergone repair of partial AVSD were studied. The records of these patients were reviewed for demographic, operative and perioperative features, follow-up echocardiographic, 24-hour Holter studies, cardiac catheterization, and clinical data. Ages ranged from 2.5 months to 43 years (mean \pm SD, $97.56 \pm$ 107.36; median, 54 months). Seventy-one $(53.78 \%$ ) patients were younger than 5 years of age and $13(9.8 \%)$ patients were older than 20 years of age. Body weight ranged between 3 and $77 \mathrm{~kg}$ (mean $\pm \mathrm{SD}$, $19.44 \pm 16.13$; median, $13.50 \mathrm{~kg}$ ). Diagnosis was established by echocardiography, cardiac catheterization, and angiocardiography. Forty-five $(34.1 \%)$ patients underwent preoperative cardiac catheterization to evaluate the associated cardiac lesions and to quantify the degree of pulmonary hypertension. Sixty-two $(46.9 \%)$ patients had associated cardiac lesions in varying combinations: patent ductus arteriosus $(n=9)$, ostium secundum atrial septal defect (ASD) $(n=19)$, left superior vena cava $(n=7)$, common atrium $(n=12)$, cor triatriatum $(n=4)$, interruption of the inferior vena cava $(\mathrm{n}=1)$, pulmonary stenosis $(\mathrm{n}=2)$, and unroofed coronary sinus $(\mathrm{n}=8)$. Seven $(5.3 \%)$ patients had Down syndrome (trisomy 21$)$. Five $(3.8 \%)$ patients had situs inversus with dextrocardia. Supraventricular arrhythmias were present in $21(15.9 \%)$ patients, and $2(1.5 \%)$ patients had congenital complete heart block. The left atrioventricular valve was regurgitant in 91 patients (mild, $\mathrm{n}=69$; moderate, $\mathrm{n}=18$; severe, $\mathrm{n}=4$ ) and the right atrioventricular valve was regurgitant in 61 patients (mild, $\mathrm{n}=30$; moderate, $\mathrm{n}=22$; severe, $\mathrm{n}=9$ ) (Table 1). LVOT obstruction was present in $4(3.1 \%)$ patients.

Thirty-nine $(29.5 \%)$ patients had additional malformations of the left atrioventricular valve apparatus: (annular dilatation $(n=8)$, large cleft, thickened, rolled out leaflet margins $(n=6)$, fenestration of the valve leaflets $(n=2)$, malpositioned papillary muscles $(n=2)$, malformed papillary muscles $(n=7)$, accessory clefts $(n=9)$, double-orifice left atrioventricular valve $(n=3)$, and parachute left atrioventricular valve $(n=2)$.

For patients who underwent preoperative cardiac catheterization $(\mathrm{n}=$ 45), systolic PA pressure ranged from 11 to $56 \mathrm{~mm} \mathrm{Hg}$ (mean $\pm \mathrm{SD}$, $24.2 \pm 10.2 \mathrm{~mm} \mathrm{Hg}$ ). Eleven (26.8\%) patients had normal PA pressure, $11(8.3 \%)$ had mild, $16(12.1 \%)$ had moderate, and $7(5.3 \%)$ had severe PA hypertension. Overall, 25.7\% (34/132) patients had mean PA pressure greater than $18 \mathrm{~mm} \mathrm{Hg}$ and PVR greater than $2.0 \mathrm{Wood}$ units $/ \mathrm{m}^{2}$ at the time of catheterization. Reversal of PVR less than 4.0 Wood units $/ \mathrm{m}^{2}$ after oxygen $(100 \%)$ and nitric oxide $(80 \mathrm{ppm})$ administration for 10 minutes in the cardiac catheterization laboratory suggested operability; such patients were taken up for definitive surgery. Thirty-five $(26.5 \%)$ patients were in
New York Heart Association (NYHA) functional class III or IV and had one or several episodes of congestive heart failure. Four (3.03\%) patients required preoperative inotropic support.

\section{ASSESSMENT OF OPERATIVE OUTCOME Cohort of Survivors}

Among the 132 original patients, there were $6(4.5 \%)$ perioperative deaths, $4(3.2 \%)$ late deaths, and $3(2.5 \%)$ patients who were lost to follow-up. Various risk factors were evaluated as to their impact on survival: year of operation, age at repair, body surface area, preoperative severity of left atrioventricular valve incompetence, preoperative NYHA functional class, aortic crossclamp time, development of perioperative heart block, preoperative mean PA pressure, and PVR.

All survivors $(n=119)$ were examined and studied between June 2006 and December 2006, which was the closing interval of the study. Age at follow-up ranged from 11 months to 47 years (mean, $157.3 \pm 124.5$ months). Postoperative evaluation consisted of quarterly clinical examination, electrocardiogram, 24-hour Holter studies, 2-dimensional echocardiography, and cardiac catheterization.

\section{Outcome Variables}

Outcome events of interest assessed were residual or recurrent ASD, left atrioventricular valve stenosis, left atrioventricular valve regurgitation, LVOT obstruction, infective endocarditis, cardiac reoperation, and arrhythmias. The patients' clinical course (survival, need for cardiac medications, NYHA functional class, occurrence of late complications) after hospital discharge was monitored.

\section{Echocardiogram}

Preoperative transthoracic 2-dimensional color-flow Doppler echocardiography was performed with a Hewlett-Packard Sonos 5500 ultrasound system (Hewlett-Packard Co, Andover, Mass) with 2.7/3.5-MHz transducer. Echocardiographic variables compared before and after the operation were atrioventricular valve stenosis and regurgitation, LVOT gradient, and systemic ventricular function.

\section{Analysis of Rhythm Changes}

Holter studies were performed on 21 patients (using a Mortara H-12 Holter unit; Mortara Instruments, Inc, Milwaukee, Wis) who were symptomatic and had electrocardiographic evidence of dysrhythmias. The diagnosis of sinus nodal dysfunction and arrhythmias was made according to the electrocardiographic criteria defined by $\mathrm{Kugler}^{\mathrm{E} 13}$ and Balaji and colleagues. $^{\text {E14 }}$

\section{Postoperative Cardiac Catheterization}

Only 10 patients of 119 survivors underwent cardiac catheterization for assessment of residual/recurrent structural lesions, ventricular function, and measurement of PA pressure and deteriorating functional status.

\section{Operative and Postoperative Management}

Intraoperative transesophageal echocardiography was performed with a Hewlett-Packard Sonos 1500 or 5500 ultrasound system on all patients both before and after surgery. We used saline flushes to determine competency of the left and right atrioventricular valve combined with prerepair and postrepair transesophageal echocardiographic evaluation to be assured of optimal results. A median sternotomy $(\mathrm{n}=120)$ or a right anterolateral thoracotomy $(\mathrm{n}=12)$ was used. Moderately hypothermic $\left(28^{\circ} \mathrm{C}-32^{\circ} \mathrm{C}\right)$ cardiopulmonary bypass was established by ascending aortic and bicaval cannulation. Antegrade cold blood cardioplegia and topical hypothermia were used for myocardial preservation. 
TABLE 1. Predictors of 0 to 16 years' mortality (related to cardiac and pulmonary hypertension) by bivariate logistic regression analysis applied to all 132 patients

\begin{tabular}{|c|c|c|c|c|}
\hline Variables & $\begin{array}{c}\text { No. of } \\
\text { patients }\end{array}$ & Death & $\begin{array}{l}\text { Risk ratio } \\
(95 \% \mathrm{CI})\end{array}$ & $\begin{array}{c}P \\
\text { value }\end{array}$ \\
\hline Age & & & $7(1.39-35.21)$ & .02 \\
\hline$>10 \mathrm{y}$ & 48 & 7 & & \\
\hline$<10 \mathrm{y}$ & 84 & 2 & & \\
\hline Body weight & & & $2.24(0.44-11.23)$ & .32 \\
\hline$<10 \mathrm{~kg}$ & 82 & 7 & & \\
\hline$>10 \mathrm{~kg}$ & 50 & 2 & & \\
\hline Sex & & & $1.15(0.29-4.49)$ & .83 \\
\hline Male & 83 & 6 & & \\
\hline Female & 49 & 3 & & \\
\hline Down syndrome & & & $2.43(0.26-22.77)$ & .43 \\
\hline Yes & 7 & 1 & & \\
\hline No & 125 & 8 & & \\
\hline Congestive heart failure & & & $6.48(1.52-27.55)$ & .01 \\
\hline Yes & 35 & 6 & & \\
\hline No & 97 & 3 & & \\
\hline Cardiothoracic ratio & & & $4.49(1.09-27.43)$ & .04 \\
\hline$>0.55$ & 55 & 7 & & \\
\hline$<0.55$ & 77 & 2 & & \\
\hline $\begin{array}{l}\text { Preoperative } \\
\text { supraventricular } \\
\text { arrhythmias }\end{array}$ & & & $4.98(1.21-20.45)$ & .02 \\
\hline Yes & 21 & 4 & & \\
\hline No & 111 & 5 & & \\
\hline $\begin{array}{r}\text { Preoperative PA } \\
\text { hypertension }\end{array}$ & & & $6.78(1.59-28.88)$ & .01 \\
\hline Yes & 34 & 6 & & \\
\hline No & 98 & 3 & & \\
\hline $\begin{array}{l}\text { Preoperative moderate-to- } \\
\text { severe left AV valve } \\
\text { regurgitation }\end{array}$ & & & $13.37(3.03-58.87)$ & .001 \\
\hline Yes & 22 & 6 & & \\
\hline No & 110 & 3 & & \\
\hline $\begin{array}{l}\text { Preoperative right } \mathrm{AV} \\
\text { valve regurgitation }\end{array}$ & & & $5.81(1.83-33.55)$ & .006 \\
\hline Yes & 31 & 6 & & \\
\hline No & 101 & 3 & & \\
\hline $\begin{array}{c}\text { Preoperative LVOT } \\
\text { obstruction }\end{array}$ & & & $5(0.46-53.66)$ & .18 \\
\hline Yes & 4 & 1 & & \\
\hline No & 128 & 8 & & \\
\hline $\begin{array}{c}\text { Additional malformations } \\
\text { of left } \mathrm{AV} \text { valve }\end{array}$ & & & $6.06(1.19-38.90)$ & .006 \\
\hline Yes & 39 & 6 & & \\
\hline No & 103 & 3 & & \\
\hline $\begin{array}{l}\text { Grossly abnormal left } \\
\text { AV valve apparatus }\end{array}$ & & & $39(7.79-195.20)$ & $<.001$ \\
\hline Yes & 12 & 6 & & \\
\hline No & 120 & 3 & & \\
\hline Preoperative ionotropes & & & $18.54(2.11-141.56)$ & .008 \\
\hline Yes & 4 & 2 & & \\
\hline No & 128 & 7 & & \\
\hline
\end{tabular}

TABLE 1. Continued

\begin{tabular}{|c|c|c|c|c|}
\hline Variables & $\begin{array}{c}\text { No. of } \\
\text { patients }\end{array}$ & Death & $\begin{array}{l}\text { Risk ratio } \\
(95 \% \mathrm{CI})\end{array}$ & $\begin{array}{c}P \\
\text { value }\end{array}$ \\
\hline $\begin{array}{l}\text { Severe postoperative } \\
\text { sepsis }\end{array}$ & & & $4.85(2.80-432.53)$ & 0.006 \\
\hline Yes & 2 & 1 & & \\
\hline No & 130 & 8 & & \\
\hline $\begin{array}{c}\text { Postoperative moderate- } \\
\text { to-severe left AV } \\
\text { valve regurgitation }\end{array}$ & & & $11.8(2.26-61.42)$ & 0.003 \\
\hline Yes & 8 & 3 & & \\
\hline No & 124 & 6 & & \\
\hline $\begin{array}{l}\text { Persistent perioperative } \\
\text { PA hypertension and } \\
\text { low cardiac output }\end{array}$ & & & $5.28(1.16-14.23)$ & 0.01 \\
\hline Yes & 31 & 5 & & \\
\hline No & 101 & 4 & & \\
\hline $\begin{array}{l}\text { Postoperative } \\
\text { supraventricular } \\
\text { arrhythmias }\end{array}$ & & & $8.14(1.90-34.84)$ & 0.005 \\
\hline Yes & 15 & 4 & & \\
\hline No & 117 & 5 & & \\
\hline Aortic crossclamp time & & & $0.89(0.22-3.49)$ & 0.87 \\
\hline$>50 \mathrm{~min}$ & 62 & 4 & & \\
\hline$<50$ min & 70 & 5 & & \\
\hline CPB time & & & $1.43(0.36-5.62)$ & 0.6 \\
\hline$>70 \mathrm{~min}$ & 49 & 4 & & \\
\hline$<70$ min & 73 & 5 & & \\
\hline
\end{tabular}

The ASD was closed with an autologous pericardial patch in 127 patients and an autogenous right atrial patch in 5 patients. A nonabsorbable monofilament suture was used in all, with interrupted mattress sutures along the crest of the ventricular septum and mitral annulus and continuous suture along the rest of the circumference. The coronary sinus was diverted to the left atrium in 40 patients, whereas it was left to drain into the right atrium in the remaining 92 patients.

If the left atrioventricular valve was competent and if it was associated with abnormal subvalvular supportive mechanism (eg, grossly malformed papillary muscles, double-orifice left atrioventricular valve, and parachute valve) $(n=12)$, it was left unrepaired. Thus, the left atrioventricular valve cleft was repaired in 120 patients and left unrepaired in the remaining 12 patients. The cleft was closed with interrupted 6-0 monofilament sutures. On the operating table, left atrioventricular valve competence was tested by injecting cold saline solution into the left ventricle. The right atrioventricular valve was also repaired in 31 patients (the cleft was repaired in 21 patients, a modified DeVega annuloplasty was used in 6, and Reed's commissuroplasty in 4 patients). Two patients needed a pulmonary valvotomy, which was done through a right atrial approach in one and through the PA in the other patient. The left atrioventricular valve reconstruction procedures entailed commissural plication, papillary muscle splitting, chordal shortening, and posterior annuloplasty.

Accessory clefts $(n=9)$ were found in all three leaflets. Their treatment was individualized on the basis of the valve function. There was no valvular regurgitation in all patients with double-orifice left atrioventricular valve; hence they were handled conservatively.

Seven $(5.5 \%)$ of 126 hospital survivors underwent reoperation. One patient was reoperated on for residual/recurrent ASD, 2 patients underwent revision/reconstruction of the left atrioventricular valve, and the remaining 4 patients underwent replacement of the left atrioventricular valve. Four 


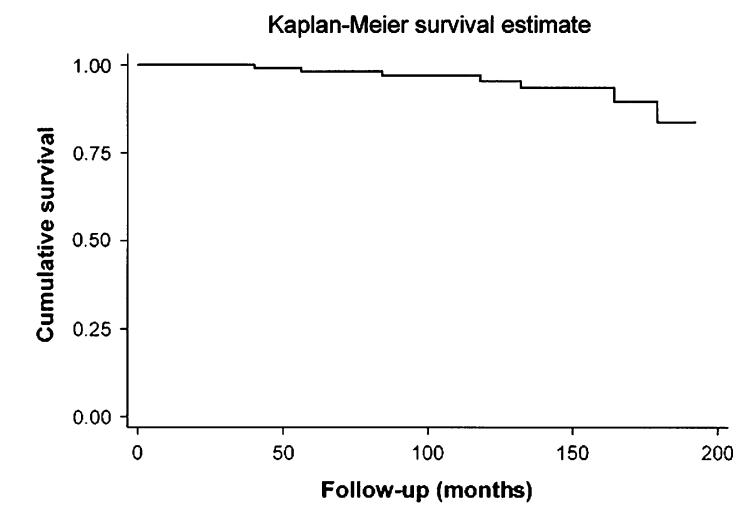

$\begin{array}{llllllllllll}\text { Follow-up (months) } & 0 & 20 & 40 & 60 & 80 & 100 & 120 & 140 & 160 & 180 & 200 \\ \text { Number at risk } & 132 & 126 & 115 & 106 & 92 & 73 & 61 & 46 & 26 & 13 & 1 \\ \begin{array}{l}\text { Cumulative } \\ \text { Survival (\%) }\end{array} & 100 & 95 & 94 & 93 & 91 & 91 & 91 & 91 & 91 & 83 & 83 \\ \text { Standard error } & 0 & 0.01 & 0.01 & 0.02 & 0.02 & 0.01 & 0.02 & 0.02 & 0.02 & 0.07 & 0.07\end{array}$

FIGURE 1. Actuarial freedom from left atrioventricular valvular reoperation in patients undergoing surgical repair of partrial atrioventricular septal defect.

$(3.03 \%)$ patients with associated LVOT obstruction underwent concomitant resection of the subaortic membrane and septal myectomy.

The replacement was performed immediate postoperatively ( $<7$ days) in 1 patient and less than 3 months, less than 10 years, and less than 15 years in 1 each. Ages at reoperation for left atrioventricular valve replacement were 5 years, 13 years, 17 years, and 27 years, respectively. The St Jude Medical mechanical prosthesis (St Jude Medical, Inc, St Paul, Minn) (27 mm, 2; 29 $\mathrm{mm}, 1 ; 31 \mathrm{~mm}, 1)$ was used in all patients. All patients undergoing left atrioventricular valve replacement had total chordal preservation, and 2-0 Ethibond sutures (Ethicon, Inc, Cincinnati, Ohio) over polytetrafluoroethylene pledgets was used in all.

All patients were routinely started on a regimen of dopamine $\left(4 \mu \mathrm{g} \cdot \mathrm{kg}^{-1}\right.$. $\left.\min ^{-1}\right)$ to increase renal perfusion and sodium nitroprusside $\left(0.54 \mu \mathrm{g} \cdot \mathrm{kg}^{-1}\right.$. $\min ^{-1}$ ) to reduce afterload and PA pressure. Patients considered to have low output syndrome $(\mathrm{n}=31)$ required dopamine, dobutamine, epinephrine, and milrinone, either isolated or in combination.

Postoperatively, left atrial and PA pressures were monitored in patients with moderate-to-severe PA hypertension and/or grossly abnormal left atrioventricular valve apparatus. Postoperatively, patients were sedated and paralyzed during the first 24 to 48 hours. PA hypertension was treated with hyperventilation, sedation, phenoxybenzamine, sildenafil citrate (INN: Sildenafil), and inhaled nitric oxide (10-15 ppm) in varying combinations as required. All patients were administered oral angiotensin-converting enzyme inhibitors after extubation $(0.5-1.0 \mathrm{mg} / \mathrm{kg}$; every 8 hours) before weaning from inotropic agents as deemed necessary by the operating surgeons. Postoperatively, digoxin, diuretics, and angiotensin-converting enzyme inhibitors were weaned at varying intervals. Amiodarone was used for intractable atrial fibrillation. The mean aortic crossclamp time was $52.86 \pm 21.38$ minutes (range, 9-129 minutes) and the cardiopulmonary bypass time was $76.34 \pm 30.71$ minutes (range, 29-270 minutes).

Both conventional (on-pump) and immediate postbypass ultrafiltration were used in patients weighing less than $10 \mathrm{~kg}$ and those with moderateto-severe PA hypertension to reduce the total body water and remove inflammatory mediators from the circulation.

Left ventricular assist devices and extracorporeal membrane oxygenation were not used for any patient in this study group. Mean duration of intensive care unit stay was $3.31 \pm 4.46$ days (range, 1-34 days), mean duration of hospital stay was $8.8 \pm 5.9$ days (range, 7-40 days), and the mean duration of ventilation was $1.67 \pm 2.74$ days (range, $1-24$ days).

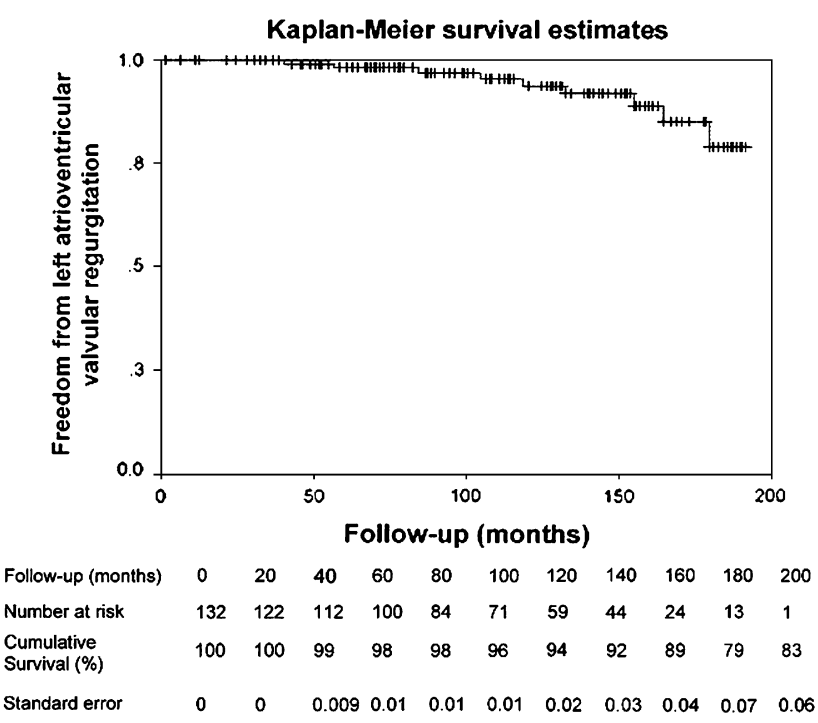

FIGURE 2. Actuarial survival curve of patients undergoing surgical repair of partial atrioventricular septal defect.

\section{Statistical Analysis}

Statistical analysis was carried out using Intercooled STATA 9.0 software (Stata Corp, College Station, Tex). Data were presented as mean \pm $\mathrm{SD} /$ median (range). Categorical variables were expressed as frequency distribution and percentages. The difference in proportions between the groups was compared by the $\chi^{2} /$ Fisher exact test. The difference in medians between the groups was compared by the Wilcoxon rank sum test. The Kaplan-Meier method was used to calculate actuarial survival as well as freedom from left atrioventricular valvular regurgitation (Figures 1 and 2).

To identify the risk factors for death, we did a logistic regression analysis and reported the results as risk ratio $(95 \%$ confidence interval $[\mathrm{CI}])$. The following variables were examined for significance with different statistical methods: age at operation, weight at operation, preoperative left atrioventricular valve insufficiency, double-orifice left atrioventricular valve, associated valvular malformations, accessory clefts, fenestration of valve leaflets, and malformed or malpositioned papillary muscles (Tables 1 and 2).

Regression analysis usually signifies independent risk factors. In this study, the patients with grossly abnormal left atrioventricular valves appear to be the same patients with unrepaired septal commissure. Inasmuch as we specifically avoided closure of the septal commissure in these patients, this will possibly unfairly impugn "an unrepaired cleft." Thus, grossly abnormal left subvalvular apparatus and unrepaired septal commissure are interdependent, and only grossly abnormal left atrioventricular valve was considered for data analysis.

\section{RESULTS \\ Early Results}

There were $6(4.5 \%)$ hospital deaths resulting from persistent postoperative PA hypertension and low cardiac output $(\mathrm{n}=5)$ and septicemia $(\mathrm{n}=1)$. Of 132 patients, patients aged less than 1 year translated into a significantly longer hospital and intensive care unit stay and the duration of mechanical ventilation $(P=.004,<.001$, and .001 , respectively).

Thirty-one $(23.5 \%)$ patients in this study had postoperative moderate PA hypertension. Of these, 22 (70.9\%) 
TABLE 2. Predictors of 0 to 16 years' mortality (cardiac and pulmonary hypertension related) by stepwise logistic regression applied to all 132 patients

\begin{tabular}{lcc}
\hline \multicolumn{1}{c}{$\begin{array}{c}\text { Step 4a: } \text { Variables } \\
\text { (covariates adjusted) }\end{array}$} & $\begin{array}{c}\text { Risk ratio } \\
\mathbf{( 9 5 \%} \mathbf{C I})\end{array}$ & $\boldsymbol{P}$ value \\
\hline Grossly abnormal left AV valve apparatus & $38.92(7.8-195.1)$ & $<.001$ \\
Preoperative PA hypertension & $6.88(1.79-38.18)$ & .02 \\
\hline$C I, C$.
\end{tabular}

$C I$, Confidence intervals; $A V$, atrioventricular; $P A$, pulmonary artery.

patients were older than 3 years of age and $5(16.1 \%)$ patients had grossly malformed left atrioventricular valvular apparatus and severe PA hypertension. The systolic PA pressure in 16 patients decreased to around half the systemic pressure intraoperatively. Subsequently, after the initial 24 hours, 15 patients had a paroxysmal hypertensive crisis and were treated with hyperventilation, sedation, phenoxybenzamine, sildenafil, and inhaled nitric oxide (10-15 ppm) in varying combinations for 72 to 96 hours. Despite current repair practices with a functioning left atrioventricular valve, an unrepaired septal commissure, and institution of the aforementioned antipulmonary hypertensive measures, 5 patients died as a result of recurrent pulmonary hypertensive episodes.

Age more than 10 years, presence of preoperative congestive heart failure, supraventricular arrhythmias, PA hypertension, moderate-to-severe left and right atrioventricular valve regurgitation, grossly abnormal left atrioventricular valve apparatus, development of severe postoperative sepsis, postoperative left atrioventricular valve regurgitation, low cardiac output, and supraventricular arrhythmias were significant negative factors for survival according to bivariate logistic regression analysis (Table 1). Multivariate logistic regression analysis identified two predictors of death after repaired AVSD. The risk of death was 38.92 (95\% CI: 7.8-195.1) and 6.88 (95\% CI: 1.79-38.18) times higher in patients with grossly malformed left atrioventricular valve and preoperative PA hypertension, respectively.

\section{Long-term Results}

Midterm mortality and morbidity. Premature late deaths occurred in 4 of $126(3.2 \%)$ hospital survivors. One patient had morphologically malformed left atrioventricular valve. Congestive cardiac failure was the cause of death in all of them. Three $(2.5 \%)$ patients were lost to follow-up. Follow-up was $97.5 \%$ complete (range, 1-192 months) and yielded 1059.29 patient-years of data with a mean followup time of 106.82 months ( $\mathrm{SD} \pm 55.04$ ).

The actuarial survival at 5 years was $98.18 \% \pm 0.01 \%$ (95\% CI: $92.91 \%-99.54 \%$ ) and at 16 years was $83.70 \%$ $\pm 0.07 \%$ (95\% CI: 62.93\%-93.39\%) (Figure 2). The actuarial freedom from left atrioventricular valve regurgitation at 192 months was $79.29 \% \pm 0.07 \%$ (95\% CI: $60.82 \%-$ $92.45 \%$ ) (Figure 1). The majority $(91.5 \%)$ of patients were in NYHA functional class I or II at their last followup visit with good left ventricular function.

Reoperation. Reoperations were performed in $7(5.8 \%)$ patients. Three $(2.5 \%)$ patients required permanent pacemaker implantation for complete and permanent atrioventricular dissociation. One patient was reoperated on for recurrent ASD 3 years after the primary procedure. Six $(5.1 \%)$ patients were reoperated on for secondary left atrioventricular valve regurgitation.

Left atrioventricular valve regurgitation. Preoperatively, varying degrees of left atrioventricular valve regurgitation were present in $91(68.9 \%)$ patients (mild, $\mathrm{n}=69$, moderate, $\mathrm{n}=18$, severe, $\mathrm{n}=4$ ). The remaining 41 $(31.1 \%)$ patients had a competent left atrioventricular valve. Postoperatively, moderate-to-severe left atrioventricular valve regurgitation was present in $6.7 \%$ (8./119) of survivors.

Two patients underwent reoperation on the second and 15 th postoperative days owing to severe left atrioventricular valve regurgitation and unstable haemodynamics. They underwent left atrioventricular valve reconstruction. The reconstruction procedures entailed commissuroplasty, chordal shortening, papillary muscle fenestration, and annular remodeling with a Teflon ring. Four patients underwent replacement of the left atrioventricular valve with a St Jude Medical mechanical prosthesis.

None of the patients who were reoperated on for recurrent left atrioventricular valvular regurgitation had incomplete or noncleft closure at the primary operation. Only 2 survivors with parachute left atrioventricular valve had mild-tomoderate left atrioventricular valvular regurgitation and were managed conservatively.

Residual or recurrent ASD. Residual or recurrent ASD was identified in 3 patients during follow-up. One underwent reoperation for hemodynamically significant left-toright shunting 3 years after the operation. The remaining 2 patients were managed medically.

Supraventricular arrhythmias. Preoperatively, supraventricular tachyarrhythmias were present in $21(15.9 \%)$ patients. Sixty-two percent $(n=13)$ of them were aged between 20 and 43 years at operation. Postoperatively, supraventricular arrhythmias were observed in $15(11.3 \%)$ patients. The occurrence of supraventricular arrhythmias, adjusted for the decade of the operation and other surgical variables, increased with increasing age at operation (risk ratio $3.98 ; 95 \% \mathrm{CI}, 2.60-18.78 ; P<.002)$.

Heart block. Two (1.5\%) patients had congenital complete heart block preoperatively. Postoperatively, there were occurrences of complete and permanent atrioventricular dissociation in $2(1.5 \%)$ patients undergoing intracardiac repair. These patients required permanent pacemaker implantation.

LVOT obstruction. Preoperatively, significant LVOT obstruction was identified in $4(3.03 \%)$ patients with a left ventricle-aorta gradient measuring between 50 and $70 \mathrm{~mm}$ 
Hg. Three $(2.3 \%)$ patients had a subaortic fibrous ring and 1 $(0.8 \%)$ patient had a fibromuscular ring. All 4 patients underwent resection of the subaortic membrane and septal myectomy. Postoperatively, residual LVOT obstruction was present in 2 patients, and $2(1.6 \%)$ patients had newonset LVOT obstruction. Inasmuch as the patients were asymptomatic and gradients measured between 25 and 40 $\mathrm{mm} \mathrm{Hg}$, no revision surgery was performed.

\section{DISCUSSION}

Despite improved outcomes of partial AVSD repair over time, several morphologic and functional issues continue to be the causative factors for late mortality and morbidity. ${ }^{\text {E1-E12, }}$ ${ }^{\text {E15-E17 }}$ Although different surgical approaches to repair the left atrioventricular valve have been described, the issue of late atrioventricular valve regurgitation remains because the pathophysiologic features of this disorder are still not completely understood. ${ }^{\text {E1-E12,E15-E17 }}$

The major finding in this investigation was the extremely variable clinical presentation with a spectrum of anatomic variations. The second important finding was the feasibility of reconstruction of the left atrioventricular valve in $91 \%$ of patients (120/132) despite older age ( $>20$ years) at presentation $(n=13)$. The third important finding was the occurrence of additional malformations of the left atrioventricular valve in $29.5 \%(\mathrm{n}=39)$ and grossly abnormal left atrioventricular valve in $9.1 \%(n=12)$ of patients respectively.

The fourth important finding was the striking and persistent difference in surgical outcome of patients with partial AVSDs with preoperative PA hypertension and moderateto-severe left atrioventricular valve regurgitation. Logistic regression analysis accounting for the effects of other factors demonstrated all the aforementioned factors as significant predictors of death after repair of partial AVSD (Tables 1 and 2).

Our management policy for repair of partial AVSDs during the past 15 years has been relatively uniform with surgical correction at the first presentation of a large left-to-right shunt with congestive heart failure or left ventricular enlargement. In this study group, the hospital mortality was $4.5 \%$, with an actuarial 5-year survival of $98.18 \% \pm$ $0.01 \%$ and a 16 -year survival of $83.70 \% \pm 0.07 \%$. These figures compare favorably with the series published after 1990. ${ }^{\text {E1-E12,E15-E17 }}$

The majority of patients with grossly abnormal left subvalvular apparatus $(\mathrm{n}=12)$ in this study had unrepaired cleft of the left atrioventricular valve. The competent mechanism of the valvular apparatus and the concerns of producing iatrogenic stenosis precluded suture closure of the left atrioventricular valve in these patients. Despite current repair practices and techniques, the risk of death was 38.92 (95\% CI: 7.8-195.1) and 6.88 (95\% CI: 1.79-38.18) times higher in patients with grossly malformed left atrioventricular valve and preoperative PA hypertension, respectively, by logistic regression analysis. Such patients with abnormal left atrioventricular valve attachments may represent a different (perhaps more severe) subset of this anomaly with a different natural history. ${ }^{\mathrm{E} 1, \mathrm{E} 4, \mathrm{E} 5, \mathrm{E} 9, \mathrm{E} 10, \mathrm{E} 12}$

As late presentation of congenital heart disease is not unusual in the developing world, it is not uncommon to be faced with the adult patient with partial AVSD with severe left atrioventricular valve regurgitation and PA hypertension. Only $84(63.6 \%)$ patients in this series were less than 10 years of age and $13(9.8 \%)$ patients were older than 20 years. Although our setting is a tertiary referral care center, the socioeconomic profile of the patients and the lack of health care insurance benefit led to delayed referral and surgery, accounting for the older age of the patients.

The late presenters are known to have deformed and malformed left atrioventricular valve apparatus with widely separated cleft and annular dilatation, rolled out valve edges, supraventricular arrhythmias, residual or recurrent left atrioventricular valve regurgitation, and residual or recurrent LVOT obstruction. These could be defined as "acquired" diseases of the valve apparatus.

\section{Left Atrioventricular Valve Stenosis and Regurgitation}

Assessing the presence or absence of left atrioventricular valve regurgitation and its degree across different time frames is difficult because of changes in technology. With the advent of intraoperative transesophageal echocardiography, the accuracy of assessment of left atrioventricular valve function both before and after repair has increased. ${ }^{\text {E1-E12,E15-E17 }}$

Reoperation rates for left atrioventricular valve regurgitation have varied between $6 \%$ and $18 \%$ in pediatric and adult series, respectively. ${ }^{\mathrm{E} 1-\mathrm{E} 12, \mathrm{E} 15-\mathrm{E} 17}$ The issue of routine cleft closure in partial AVSD to decrease reoperation remains controversial. It has been suggested that routine valvuloplasty may not be required because of the tendency of thickening of left atrioventricular valve leaflets, leading to spontaneous closure of the cleft. ${ }^{\text {E1-E12,E15-E17 }}$

Studies have demonstrated that in partial AVSD, the left chordae are often short and the leaflet motion thus restricted. The papillary muscles are also displaced within the left ventricle in a subset of patients, and these malformed or malpositioned papillary muscles cause alteration in the mechanics of the left atrioventricular valve in partial AVSD. ${ }^{\text {E18-E21 }}$ Because of the small number of patients with this malformation in our series, we could not address any specific alterations of the papillary muscles as a possible causative factor for late atrioventricular valvular regurgitation. However, all types of additional valvular malformations seemed to increase the incidence of late atrioventricular valvular regurgitation except perhaps the presence of a doubleorifice left atrioventricular valve.

In this series, $91 \%$ of patients had successful repair of the left atrioventricular valve with good long-term results 
despite older age ( $>20$ years) at presentation $(n=13)$, the presence of severe left subvalvular abnormalities $(9.1 \%)$, and additional malformations of the left atrioventricular valve apparatus in $29.5 \%$ of patients. Of 12 patients with morphologically malformed left atrioventricular valve apparatus and unrepaired septal commissure, $6(50 \%)$ died in the immediate and late postoperative periods owing to pulmonary hypertensive crises and congestive cardiac failure with a functioning left atrioventricular valve.

Over the time period in this study review (1991-2006), there is a strong potential for time bias and related technical and outcome changes over time. One such potential bias is replacement $(n=4)$ versus repair $(n=2)$ of the left atrioventricular valve. We concur with the observations of other investigators that the majority of patients with partial AVSDs and recurrent left atrioventricular valvular regurgitation can undergo repair with a myriad of techniques, that is, cleft reclosure, commissural plication, chordal shortening, papillary muscles splitting, annuloplasty of the left atrioventricular valve, and resuspension of the left atrioventricular valve apparatus with artificial chordae. Rigorous preoperative and intraoperative transesophageal echocardiographic assessment and systematic operative examination of the annulus, leaflets, chordae, and papillary muscles are mandatory in all patients with partial AVSDs undergoing surgery. Valves that are competent on preoperative and intraoperative examinations, including double-orifice left atrioventricular valve, are usually not disturbed whether or not a cleft is present. Also, if there is a likelihood of iatrogenic left atrioventricular valve stenosis because of severe subvalvular deformity, the valve usually is not disturbed. ${ }^{\text {E1-E12,E15-E21 }}$

Regurgitant valves are repaired systematically. If the regurgitation corresponds to the cleft, the gap is closed. Inaccurate cleft approximation may produce central insufficiency and excessive cleft closure can result in stenosis. Care should be taken to precisely size the septal patch to avoid annular distortion. Although revision reconstruction of the left atrioventricular valve could be successfully performed on $2(1.5 \%)$ patients in this series, $4(3 \%)$ had to undergo replacement of the left atrioventricular valve, because their valves were deemed unsuitable for reconstruction by the operating surgeons. Incidentally, none of the patients who were reoperated on for recurrent left atrioventricular valvular insufficiency had incomplete or noncleft closure at the primary operation.

\section{LVOT Obstruction}

The reported incidence of LVOT obstruction after surgical repair of partial AVSD ranges from 3\% to $7 \%$. E1-E12,E15-E17,E20-E25 Most common causes of subaortic stenosis in partial AVSD include (1) discrete fibromuscular ring, (2) tunnel-like obstruction, and (3) attachment of left valvular and subvalvular tissue attached to the LVOT. Because of the predisposing anatomy, hemodynamically sig- nificant LVOT obstruction may appear after repair of ostium primum ASD and does not warrant reoperation. Because of the elongated LVOT, adequate relief of obstruction may be difficult in these patients.

In our study, significant LVOT obstruction requiring surgical resection was present in $4(3.1 \%)$ patients. In 2 other patients, a new-onset LVOT gradient, between 10 and 15 $\mathrm{mm} \mathrm{Hg}$, respectively, developed postoperatively. Inasmuch as they were asymptomatic, no operative intervention was contemplated.

Current wisdom dictates an individualized management protocol depending on the anatomic problems, namely fibromuscular resection and myectomy, subaortic fibromuscular resection, septoplasty, or modified Konno. ${ }^{\text {E16,E26,E27 }}$ Longterm follow-up is essential for diagnosis owing to delayed appearance and lack of reliable clinical signs.

\section{Supraventricular Arrhythmias}

Published literature documents an increased incidence of supraventricular arrhythmias and atrioventricular block in untreated patients with partial AVSD. The reported incidence of supraventricular arrhythmias was $25 \%$ and $80 \%$ by the age of 30 years and 45 years, respectively. ${ }^{\text {E1-E12,E18-E22,E28 }}$

Heart block after partial AVSD repair remains a perplexing problem given our understanding of conduction system anatomy and rigorous efforts to avoid the atrioventricular node during patch placement. The choice of the placement of the suture line should be based on the anatomic findings at operation. The presence of a tough fibrous ridge allows suturing on the left side of the septum. The absence of a ridge favors placement on the right side, staying away from the atrioventricular node area near the coronary sinus. Complete heart block is not purely a surgical complication, inasmuch as $1.5 \%(2 / 132)$ patients in our series and $22.2 \%(6 / 27)$ patients in Somerville's series ${ }^{\mathrm{E} 28}$ manifested clinical deterioration owing to heart block without surgical repair.

\section{Study Limitations}

A limitation of this study is the low number of patients with partial AVSD and grossly malformed left atrioventricular valves. The population is also influenced by the late presenters owing to natural selection, as outlined in the text.

\section{CONCLUSIONS}

We conclude that (1) patients with partial AVSD undergoing surgical correction using a myriad of techniques will in general do well with minimal mortality, morbidity and excellent long-term results; (2) recurrent left atrioventricular valvular regurgitation is the commonest cause of reoperation. Transesophageal echocardiography combined with systematic individualized valvuloplasty techniques should 
reduce the incidence of recurrent postoperative left atrioventricular valvular regurgitation. Early surgical repair might prevent progression of annular dilatation and permit better preservation of valve structures; (3) the presence of PA hypertension, moderate-to-severe left atrioventricular valve regurgitation, and grossly malformed left atrioventricular valve apparatus are independent predictors for mortality and defect-related morbidity after surgical repair; and (4) finally, because of the morphologic hetero- geneity of the left atrioventricular valvular apparatus, LVOT, and displaced conduction system, an individualized management algorithm customized to each patient's specific anatomy would be helpful. Late complications, although uncommon, necessitate continuous life-long follow-up.

The authors are grateful to Mr. Shankar Sharma for preparation of the manuscript. 


\section{DEFINITIONS}

Partial or incomplete AVSD is defined as one with no major interventricular communications and with two separate

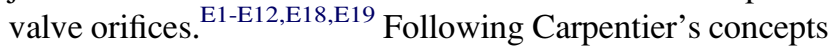
on this malformation, we used the terms left atrioventricular valve and right atrioventricular valve instead of mitral valve and tricuspid valve, respectively. ${ }^{\text {E19 }}$ The term septal commissure was used instead of cleft to indicate the gap between the left superior and left inferior leaflets. A double-orifice left atrioventricular valve was considered to be present when there were two separate valve orifices, each supported by a distinct subvalvular apparatus. ${ }^{\text {E1-E12,E18,E19 }}$

A fenestration or perforation of the left atrioventricular valve is an orifice, congenital or acquired in origin, well separated from the main orifice but not supported by a chordal

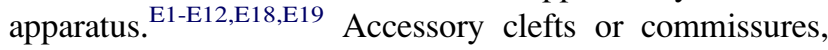
defined as radial openings from the free edge of a leaflet, were complete (up to the annulus) or incomplete (partially splitting the leaflet). ${ }^{\text {E1-E12,E18,E19 }}$

Anomalous positions of the papillary muscles are common in AVSD and are difficult to classify. Therefore, only extreme malpositions, that is, potentially parachute mitral valve or extreme lateralization of the papillary muscles, were considered. Malformations of papillary muscles included abnormally thick muscles with rudimentary or absent chordal apparatuses inserted directly into the undersurface of the leaflets and multiple thin muscles with abnormal insertions into the ventricular walls.

Patients with malformed papillary muscles $(n=7)$, double-orifice left atrioventricular valve $(\mathrm{n}=3)$, and parachute left atrioventricular valve $(n=2)$ were grouped together for data analysis and were considered as having a grossly abnormal left atrioventricular valve.

Late left atrioventricular valve insufficiency was defined as such because it was not evident at the end of the operation. ${ }^{\text {E1-E12,E18,E19 }}$ Left atrioventricular valve regurgitation was considered to be present if the patient underwent operation for regurgitation or if there was clinical, angiographic, or Doppler echocardiographic evidence for left atrioventricular valve regurgitation. The severity of regurgitation was based on the severity assigned by the attending physician and recorded in the medical record. The severity assigned was associated with the first recorded observation of regurgitation after the primary operation.

Left atrioventricular valve regurgitation was graded as per the recommendation of the American Society of Echocardiographic Criteria. ${ }^{\mathrm{E} 29}$

$0 \rightarrow$ None/trivial $(<5 \%$ of left atrioventricular valve area)

$1 \rightarrow$ Mild (5\%-20\% of left atrioventricular valve area)

$2 \rightarrow$ Moderate $(20 \%-40 \%$ of left atrioventricular valve area)

$3 \rightarrow$ Severe $(>40 \%$ of left atrioventricular valve area)
Left atrioventricular valve stenosis was considered to be present if the patient underwent operation or reoperation for stenosis or if there was a left atrial-left ventricular enddiastolic pressure gradient of more than $5 \mathrm{~mm} \mathrm{Hg}$ by cardiac catheterization or Doppler echocardiography.

LVOT obstruction was deemed to be present if there was a pressure gradient of $20 \mathrm{~mm} \mathrm{Hg}$ or more across the LVOT measured at cardiac catheterization (peak-to-peak gradient) or Doppler echocardiography (mean gradient) or if an operation for relief of obstruction was performed.

A clinically significant arrhythmia was defined as one for which an antiarrhythmia drug (excluding digoxin) treatment or a pacemaker was required. ${ }^{\text {E13,E14 }}$ The date of onset of the event of interest was based on the date of documentation of that event most proximal to the date of the original operation.

On the basis of systolic PA pressure as measured by cardiac catheterization or on echocardiography on the basis of the velocity of tricuspid regurgitation, pulmonary hypertension was graded as follows: none (systolic PA pressure $<18$ $\mathrm{mm} \mathrm{Hg}$ ), mild (systolic PA pressure 19-30 mm Hg), moderate (systolic PA pressure 31-50 mm Hg), and severe (systolic PA pressure $>50 \mathrm{~mm} \mathrm{Hg}$.) An operation was classified as an emergency if the patient was taken to the operating room within the first 24 hours after presentation to hospital for hemodynamic or ventilatory compromise.

Perioperative death was defined as death that occurred within the first 30 postoperative days. Early reoperations were defined as those that occurred within 30 days.

\section{Low Cardiac Output Syndrome in Repaired Partial AVSD}

Low cardiac output syndrome was diagnosed if the patient required inotropic support (dopamine [4-10 $\mu \mathrm{g} \cdot \mathrm{kg}^{-1}$. $\left.\min ^{-1}\right]$, dobutamine $\left[5-10 \mu \mathrm{g} \cdot \mathrm{kg}^{-1} \cdot \min ^{-1}\right]$, epinephrine $\left[0.01-0.1 \mu \mathrm{g} \cdot \mathrm{kg}^{-1} \cdot \min ^{-1}\right]$, and milrinone $[50 \mu \mathrm{g} / \mathrm{kg} \mathrm{IV}$ bolus followed by $\left.0.375-0.75 \mu \mathrm{g} \cdot \mathrm{kg}^{-1} \cdot \mathrm{min}^{-1}\right]$ ), either isolated or in combination in the operating room or in the intensive care unit to maintain stable hemodynamics in the absence of residual structural lesions and mechanical external compression after correction of all electrolytes or blood gas abnormalities and after adjusting the preload to its optimal value. Low output syndrome was also diagnosed if there was an increasing requirement of the aforementioned inotropes along with afterload reduction using sodium nitroprusside. Patients who received less than $4 \mu \mathrm{g} \cdot \mathrm{kg}^{-1} \cdot \mathrm{min}^{-1}$ of dopamine to increase renal perfusion were not considered to have low output syndrome.

Invasive monitoring to measure cardiac output directly (Swan-Ganz catheter [Edwards LifeSciences, Irvine, Calif], PA pressure line, and thermistors) is cumbersome and hazardous in children and is generally avoided in our setup except in complex cases. We generally limit intracardiac 
monitoring to right atrial, left atrial, and PA pressure lines as deemed necessary by the operating surgeons.

Accordingly, under the definition of low output syndrome after repaired partial AVSD, an integration of relevant clinical, laboratory, and bedside echocardiographic criteria were used. The criteria for diagnosis were cold extremities, absent pedal pulses, decreased toe temperature, reduced systolic pressure, impaired renal function, oliguria $\left(<1.0 \mathrm{~mL} \cdot \mathrm{kg}^{-1} \cdot \mathrm{h}^{-1}\right)$, metabolic acidosis, increased serum lactate levels $(\geq 2 \mathrm{mmol} / \mathrm{L} \geq 2$ hours), low mixed venous oxygen saturation $(\leq 50 \%)$, and blunt sensorium in the absence of residual structural lesions.

\section{E-References}

E1. Welke KF, Morris CD, King E, Komanapalli C, Reller MD, Ungerleider RM. Population-based perspective of long-term outcomes after surgical repair of partial atrioventricular septal defect. Ann Thorac Surg. 2007;84:624-8.

E2. El-Najdawi EK, Driscoll DJ, Puga FJ, Dearani JA, Spotts BE, Mohney DW, et al. Operation of partial atrioventricular septal defect: a forty-year review. J Thorac Cardiovasc Surg. 2000;119:880-9.

E3. Murashita T, Kuborta T, Obha J, Aoki T, Matano J, Yasuda K. Left atrioventricular valve regurgitation after repair of incomplete atrioventricular septal defect. Ann Thorac Surg. 2004;77:2157-62.

E4. Al-Hay AA, Lincoln CR, Shore DF, Shinebourne EA. The left atrioventricular valve in partial atrioventricular septal defect: management strategy and surgical outcome. Eur J Cardiothorac Surg. 2005;27:932-3.

E5. Manning PB. Partial atrioventricular canal: pitfalls in technique. Sem Thorac Cardiovasc Surg Pediatr Card Surg Annu. 2007;10:2-6.

E6. Soufflet V, Daenen W, Van Devk K, Troost E, Budts W. Repair for partial and complete atrioventricular septal defect: single center experience and long-term results. Acta Clin Belg. 2005;60:236-42.

E7. Pretre R, Dave H, Kadner A, Bettex D, Turina MI. Direct closure of septum primum in atrioventricular canal defects. J Thorac Cardiovasc Surg. 2004;127: 1678-81.

E8. Cope JT, Fraser GD, Kouretas PC, Kron IL. Complete versus partial atrioventricular canal: equal risks of repair in the modern era. Ann Surg. 2002;236: 514-21.

E9. Jenielity M, Perek B, Palu SZ, Kiewicz L, Dyszkiewicz W. Results of surgical repair of ostium primum atrial septal defect in adult patients. J Heart Valve Dis. 2001; 10:525-9.

E10. Aubert S, Henaine R, Raisky O. Atypical forms of isolated partial atrioventricular septal defect increases the risk of initial valve replacement and reoperation. Eur J Cardiothorac Surg. 2005;28:223-8.

E11. Lukacs L, Szanto G, Kassai I, Lengyel M. Late results after repair of partial atrioventricular septal defects in adolescent and adults. Texas Heart Inst J. 1992;19: 265-9.
E12. Abbruzzese PA, Napoleione A, Bini RM, Annecchino FP, Merlo M, Parenzan L. Late left atrioventricular valve insufficiency after repair of partial atrioventricular septal defects: anatomical and surgical determinants. Atrioventricular septal defect. Ann Thorac Surg. 1990;49:111-4.

E13. Kugler JD. Sinus node dysfunction. In: Gillette PC, Garson A, eds. Pediatric arrhythmias: electrophysiology and pacing. 1st ed. Philadelphia: WB Saunders; 1990:250-300.

E14. Balaji S, Gewillig M, Bull C, de Leval M, Deanfield E. Arrhythmias after the Fontan procedure. Circulation. 1991;84(5 Suppl):III162-7.

E15. Kuralay E, Ozal E, Demirkilic U, Cingoz F, Tatar H. Left ventricular valve repair technique in partial atrioventricular septal defects. Ann Thorac Surg. 1999;68: 1746-50.

E16. Permut LC, Mehta V. Late results and reoperation after repair of complete and partial atrioventricular canal defect. Semin Thorac Cardiovasc Surg. 1997;9: 44-54.

E17. Tekin G, Tekin A, Yildirim SV, Yigit F. Long-term survival with partial atrioventricular septal defect. Int J Cardiol. 2007;115:E116-7.

E18. Becker AE, Anderson RH. Atrioventricular septal defects: what's in a name? J Thorac Cardiovasc Surg. 1982;83:461-9.

E19. Carpentier A. Surgical anatomy and management of the mitral component of atrioventricular canal defects. In: Anderson RH, Shinebourne EA, eds. Paediatric cardiology 1977. London: Churchill Livingstone; 1978:477-86.

E20. Silverman NH, Zuberbuhler JR, Anderson RH. Atrioventricular septal defects: cross-sectional echocardiographic and morphologic comparisons. Int J Cardiol. 1986;13:309-31.

E21. David I, Castaneda AR, Van Praagh R. Potentially parachute mitral valve in common atrioventricular canal. J Thorac Cardiovasc Surg. 1982;84: 178-82.

E22. Reeder GS, Danielson GK, Steward JB, Driscoll DJ, Tajik A. Fixed subaortic stenosis in atrioventricular canal defect: Doppler echocardiographic study. J Am Coll Cardiol. 1992;20:386-94.

E23. Bergin ML, Warnes CA, Tajik AJ, Danielson GK. Partial atrioventricular cana defect: long term follow up after initial repair in patients $\geq 40$ years old. $J A m$ Coll Cardiol. 1995;25:1189-94.

E24. Gatzoulis MA, Hechter S, Webb GD, Williams WG. Surgery for partial atrioventricular septal defect in the adult. Ann Thorac Surg. 1999;67:504-10.

E25. Burke R, Horvath K, Landzberg M, Hyde P, Collins J. Long-term follow-up after surgical repair of ostium primum atrial septal defect in adults. J Am Coll Cardiol. 1996;27:696-9.

E26. DeLeon SY, Ilbawi MN, Wilson Wr Jr, Arcilla RA, Thilenius OG, Bharati S, et al. Surgical options in subaortic stenosis associated with endocardial cushion defects. A. nn Thorac Surg. 1991;52:1076-83.

E27. Cooley DA, Garrentt JR. Septoplasty for left ventricular outflow obstruction without aortic valve replacement: a new technique. Ann Thorac Surg. 1986; 42:445-8.

E28. Somerville J. Ostium primum defect: factors causing deterioration in natural history. Br Heart J. 1965;27:413-9.

E29. Cheitlin MD, Armstrong WF, Aurigemma GP, Beller GA, Bierman FZ, Davis JL, et al. Guideline update for the clinical application of echocardiography: summary article. J Am Soc Echocardiogr. 2003;16:1091-110. 